\title{
Rancangan Bangunan Sistem Pengendali Suhu Kelembaban Dan Cahaya Pada Rumah Walet Berbasis Microkontroler
}

\author{
Usman $^{1}$, Sitti Harlina ${ }^{2}$, Adhy Rizaldy ${ }^{3}$ \\ STMIK Dipanegara Makassar ${ }^{12}$, UIN Alauddin Makassar ${ }^{3}$ \\ usman@dipanegara.ac.id ${ }^{1}$, sittiharlina@dipanegara.ac.id ${ }^{2}$, adhy.rizaldy@uin-alauddin.ad.id ${ }^{3}$
}

\begin{abstract}
ABSTRAK
Burung walet merupakan ternak unggas yang dibudidayakan dengan sarang sebagai produksi utama. Umumya burung wallet menyenangi tempat yang bersuhu hangat sebagai tempat tinggalnya untuk membuat sarang, selain itu keadaan suhu dan kelembaban udara yang stabil dapat menghasilkan sarang burung walet yang berkualitas sehingga memiliki harga jual yang tinggi. Oleh sebab itu penerangan yang mirip dengan gua-gua alami yang remang-remang maupun gelap pada umumnya sangat disukai oleh burung walet untuk dijadikan sebagai sarang, sehingga peternak walet biasanya menggunakan berbagai media untuk membuat ruangan jadi gelap, seperti menggunakan cat dinding warna hitam, namun hal ini tidak disukai oleh burung walet karena umumnya sangat sensitif terhadap bau yang pekat sehingga hanya akan membuat burung walet tidak tinggal di dalam ruangan tersebut. Rancangan sistem pengendali suhu kelembaban dan cahaya pada rumah walet berbasis mikrokontroller ini dirancang dengan tujuan untuk mempermudah peternak melakukan pengontrolan secara berkala. Hasil penelitian ini diharapkan dapat memberikan keriganan bagi para peternak sehingga mereka tidak terlalu banyak membuang waktu untuk mengurus rumah walet.
\end{abstract}

Kata kunci : Suhu dan Kelembaban, Cahaya, rumah wallet

\section{ABSTRACT}

Swallows are poultry farmed with nests as the main production. Generally, the bird wallet likes warm temperatures as a place to live to make a nest, besides that a stable temperature and humidity can produce high quality swallow nests so that it has a high selling price. Therefore lighting that is similar to natural caves that are dim or dark in general is very preferred by swallow birds as a nest, so swallow breeders usually use various media to make the room dark, such as using black wall paint, but this is not liked by swifts because generally it is very sensitive to thick odor so that it will only make the swallow not live in the room. The design of humidity and light temperature control systems in microcontroller-based swallow houses is designed with the aim of making it easier for breeders to carry out regular control. The results of this study are expected to provide relief for farmers so that they do not waste too much time managing the swallow's house.

Keywords: Temperature and Humidity, Light, home wallet

\section{PENDAHULUAN}

Burung walet merupakan ternak unggas yang dibudidayakan dengan sarang sebagai produksi utama. Burung wallet memiliki beberapa cirri khas yang tidak dimiliki oleh burung lain. Ciri khas tersebut diantaranya melakukan hamper segala aktivitasnya di udara seperti makan dan bereproduksi, sehingga burung wallet sering disebut dengan burung layang- 
layang. Burung walet merupakan burung pemakan serangga yang bersifat aerial dan suka meluncur. Burung ini berwarna gelap, terbangnya cepat dengan ukuran tubuh sedang atau kecil, dan memiliki sayap berbentuk sabit yang sempit dan runcing, kakinya sangat kecil begitu juga paruhnya dan jenis burung ini tidak pernah hinggap di pohon. Selain itu, cirri yang paling khas dari jenis burung ini yaitu kemampuannya dalam menghasilkan sarang yang bernilai jual tinggi.

Terdapat beberapa jenis burung wallet yang ditemukan di Indonesia, salah satunya adalah Collocalia fuciphaga, spesies ini merupakan burung wallet yang mampu menghasilkan sarang berwarna putih dan paling disukai konsumen. Burung wallet (Collocalia fuciphaga) tersebar diberbagai pulau. Umumya burung wallet menyenangi tempat yang bersuhu hangat sebagai tempat tinggalnya untuk membuat sarang, selain itu keadaan suhu dan kelembaban udara yang stabil dapat menghasilkan sarang burung walet yang berkualitas sehingga memiliki harga jual yang tinggi . Penerangan yang mirip dengan gua-gua alami yang remang-remang maupun gelap pada umumnya sangat disukai oleh burung walet untuk dijadikan sebagai sarang, sehingga peternak walet biasanya menggunakan berbagai media untuk membuat ruangan jadi gelap, seperti menggunakan cat dinding warna hitam, namun hal ini tidak disukai oleh burung walet karena umumnya sangat sensitif terhadap bau yang pekat sehingga hanya akan membuat burung walet tidak tinggal di dalam ruangan tersebut [1]

\subsection{Penelitian Terkait}

Gedung untuk rumah walet harus memiliki suhu, kelembaban yang stabil Oleh karena itu, biasanya peternak harus melakukan pengukuran suhu dan kelembaban yang dilakukan dengan menggunakan thermometer dan hygrometer3-4 kali seminggu untuk mengetahui apakah suhu dan kelembabannya sesuai. Suhu gua alami yang berkisar antara $26-28^{\circ} \mathrm{C}$ dan kelembaban $\pm 80-90 \%[2]$. Intensitas cahaya yang disukai oleh burung wallet untuk bersarang adalah 0 lux (gelaptotal) atau 0,2 - 0,5 foot candle (fc) yang setara dengan 2 nyala lilin.[3]

\subsection{Karakteristik Suhu Ruangan}

Di lapisan udara selalu terdapat uap air. Kadar uap air yang terdapat di udara disebut juga kelembaban atau kelengasan udara. Kelembaban udara dapat diartikan banyaknya kandungan uap air dalam massa udara. Kelembaban udara dapat dihitung dengan menggunakan alat hygrometer. Kelembaban udarah menggambarkan kandungan uap air diudara yang dapat dinyatakan sebagai kelembaban mutlak (relatif) maupun definisi tekanan uap air kelembaban mutlak adalah kandungan uap air per satuan volume [4]. Kelembaban udara dibedakan atas kelembaban mutlak (absolut) dan kelembaban relatif.

1) Kelembaban Mutlak (Absolut)

Kelembaban mutlak atau kelembaban absolut adalah jumlah massa uap air per satuan volume udara.

Kelembaban mutlak dinyatakan dalam gram $/ \mathrm{m}^{3}$. Kelembaban mutlak menyatakan kelembaban aktual yang pada saat tertnetu benar-benar terjadi. Kelembaban mutlak jarang digunakan dalam perhitungan karena dapat berrubah-ubah akibat adanya perubahan suhu udara.

2) Kelembaban Relatif (Nisbi)

Kelembaban relatif adalah perbandingan jumlah uap air yang terkandung di udara (kelembaban mutlak/absolut) dengan jumlah uap air maksimal (jenuh) di dalam udara pada temperatur dan tekanan udara yang sama. Kelembaban relatif dinyatakan dalam persen.

\subsection{LDR}

LDR adalah suatu bentuk komponen yang mempunyai perubahan resistansi yang besarnya tergantung pada cahaya. Karak teristik LDR terdiri dari dua macam yaitu Laju Recovery dan Respon Spektral[5] 


\section{Laju Recovery}

Bila sebuah LDR dibawa dari suatu ruangan dengan level kekuatan cahaya tertentu ke dalam suatu ruangan yang gelap, maka bisa kita amati bahwa nilai resistansi dari LDR tidak akan segera berubah resistansinya pada keadaan ruangan gelap tersebut. Na-mun LDR tersebut hanya akan bisa menca-pai harga di kegelapan setelah mengalami selang waktu tertentu. Laju recovery meru-pakan suatu ukuran praktis dan suatu ke-naikan nilai resistansi dalam waktu tertentu.

\section{Respon Spektral}

LDR tidak mempunyai sensitivitas yang sama untuk setiap panjang gelombang cahaya yang jatuh padanya (yaitu warna). Bahan yang biasa digunakan sebagai penghantar arus listrik yaitu tembaga, aluminium, baja, emas dan perak. Dari kelima bahan tersebut tembaga merupakan penghantar yang paling banyak, digunakan karena mempunyai daya hantaryang baik (TEDC,1998)

\subsection{Relay}

Relay adalah saklar (switch) elektrik yang bekerja berdasarkan medan magnet. Relay terdiri dari suatu lilitan dan switch mekanik.[5] Switch mekanik akan bekerja jika ada arus listrik yang mengalir melalui lilitan. Susunan kontak pada relay adalah:

Normally Open : Relay akan menutup bila dialiri arus listrik.

Normally Close : Relay akan membuka bila dialiri arus listrik.

Changeover : Relay ini memiliki kontak tengah yang akan melepaskan diri dan membuat kontak lainnya berhubungan.

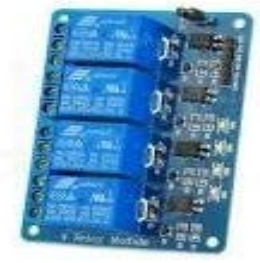

Gambar 1. Relay

\section{METODE PENELITIAN}

Proses penelitian dan perancangan system ini dilaksanakan sejak minggu kedua bulan Juni 2018 sampai minggu keempat bulan september 2018. Untuk melakukan analisa dan mendapatkan data berdasarkan latar belakang masalah yang diajukan maka penulis melakukan penelitian pada Lab Mikrokontroller STMIK Dipanegara Makassar.

\subsection{Alat dan Bahan}

a. Arduino Uno R3 Atmega328

b. LCD $16 \times 2$

c. Gear Micro Servo Motor Tower Pro SG90

d. Relay 2 Chanel dan 1 Chanel 5 Volt

e. Sensor DHT11

f. Element (Heater) 220 volt

g. FAN Power Supply Happy

h. Penyemprot 12 volt dan Gorden [6], [7], [8] 


\section{HASIL DAN PEMBAHASAN}

\subsection{Rancangan System}

Adapun rancangan sistem yang akan dibangun dapat dilihat pada ga mbarsebagai berikut:

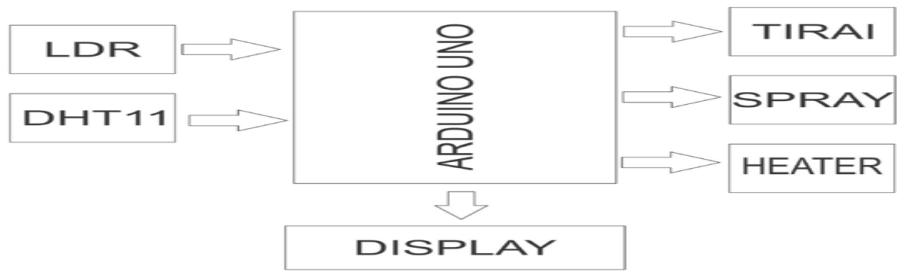

Gambar 2 Diagram Blok

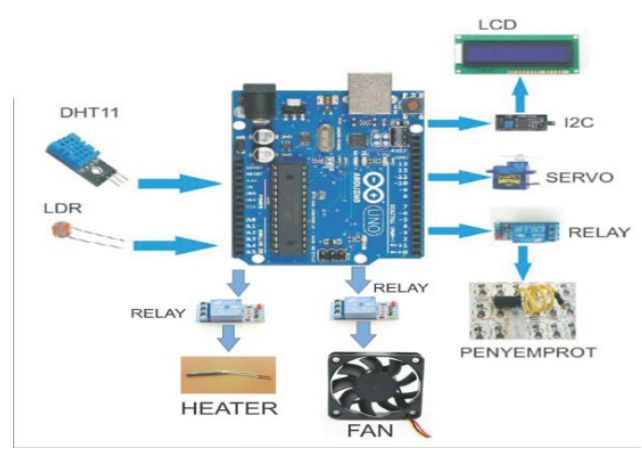

Gambar 3 Rancangan Sistem

Alat Prototipe ini dibangun menggunakan mikrokontroller Arduino dengan menggunakan sensor pengukur kelembaban RH (Relative Humidity). Alat ini dibuat untuk mengetahui kelembaban uap air yang ada pada rumah wallet. System utama pada control kelembaban ini diatur oleh mikrokontroller. Input mikrokontroller ini diperoleh dari sensor kelembaban untuk mendapatkan nilai kelembaban. Data dari sensor tersebut akan ditampilkan nilainya pada LCD. Tujuan dari pemasangan Heater (pemanas) adalah agar keadaan temperature dalam rumah walet bersifat homogen (merata) sehingga pemanasan akan sama pada semua daerah. Dengan memanfaatkan Fan / kipas yang berguna untuk menyebarkan panas sehingga keadaan suhu rumah wallet merata (homogen) sedangkan fungsi dari pemesangan spray adalah guna untuk menyemprot runagan apabila ruangan melebihi suhu $29^{0}$ C. Penggunaan realay yang terhubung ke heater berfungsi untuk memacu agar pada saat sensor suhu kelembaban terpenuhi maka heater akan bekerja, penggunaan relay terhubung ke spray berfungsi untuk memacu agar sensor suhu kelembaban terpenuhi maka spray akan berfungsi sedangkan relay yang terhubung ke fan/kipas sama fungsinya dengan yang terhubung ke heater dan spray. LDR berfungsi untuk mengatur cahaya pada rumah wallet agar cahaya yang masuk pada rumah wallet tidak berlebihan dengan memanfaatkan motor servo sebagai pengontrol buka dan tutup tirai berwarna hitam apabila cahaya yang masuk lebih kecil dari $0.5 \mathrm{fc}$ maka tirai akan terbukan dan apabila cahaya lebih dari $0.5 \mathrm{fc}$ maka tirai akan tertutup.

\subsection{Perancangan dan Pengujian Alat}

Dalam implementasi perancangan alat ini terdiri dari rangkaian minimum mikrokontroler, sensor cahaya, sensor suhu kelembaban yang berfungsi sebagai pemicu dari mendeteksi jika terjadi perubahan suhu ruangan dan nilai cahaya yang masuk pada ruangan. 


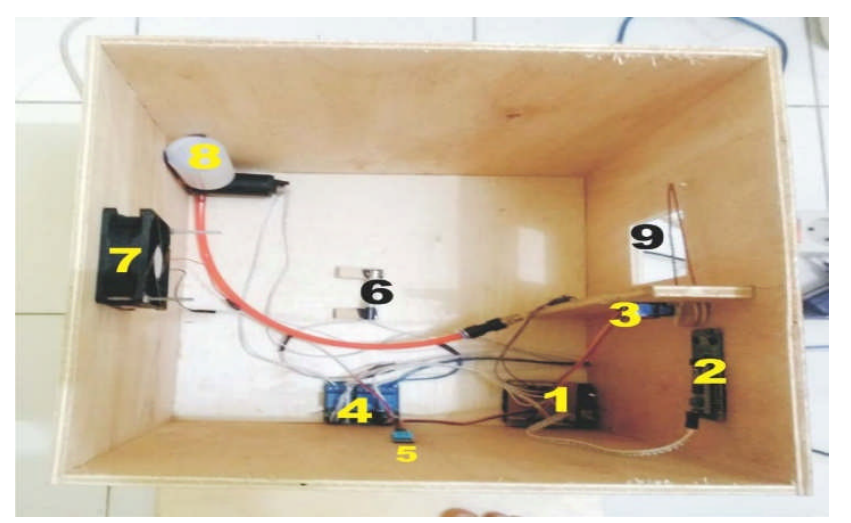

Gambar 4 Tampak Atas

Ket:

1. Arduino Uno R3 Atmega328

2. LCD $16 \times 2$

3. Gear Micro Servo Motor Tower Pro SG90

4. Relay 2 Chanel dan 1 Chanel 5 Volt

5. Sensor DHT11

6. Element (Heater) 220 volt

7. FAN Power Supply Happy

8. Penyemprot 12 volt

9. Gorden

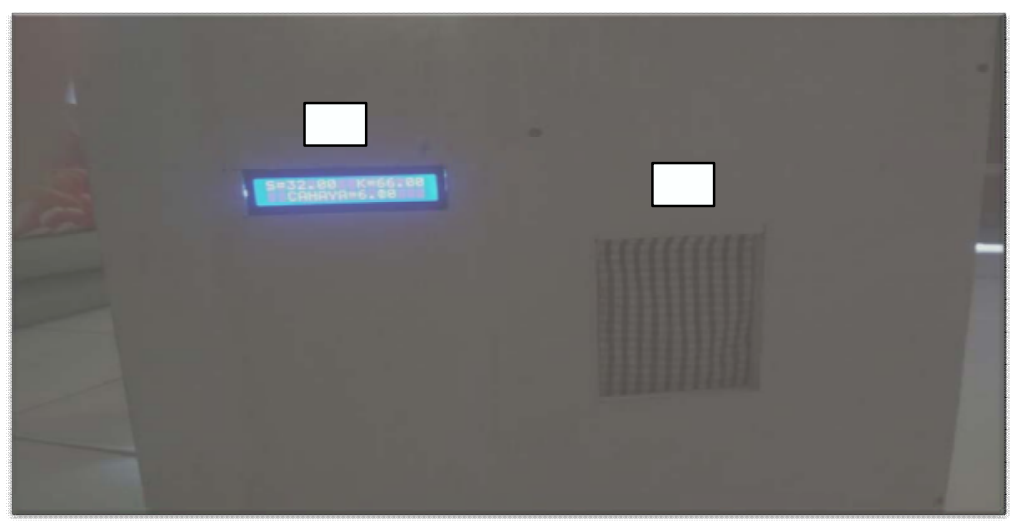

Gambar 5 Tampak Depan

Ket

1. LCD 16x2, 2. Gorden Keterangan pada LCD, 3. S= Nilai Suhu

4. $\mathrm{K}=$ Nilai Kelembaban, 5. Cahaya= Nilai Cahaya

\subsection{Perancangan Konstruksi Rumah Walet}

Sebelum kami membuat Bagunan Sistem Pengendali Suhu Kelembaban dan Cahaya Pada Rumah Walet ini terlebih dahulu kami membuat gambaran desain agar nantinya mempermudah kami dalam membuat bentuk aslinya, ada pun software yang kami gunakan adalah coreldraw $\mathrm{X} 4$, berikut konstruksi keseluruhan: 


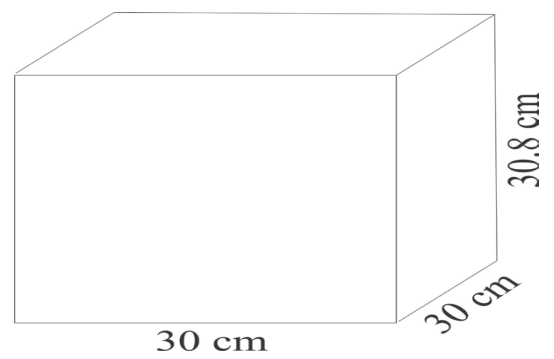

Gambar 6 Desain Bagunan

\subsection{Perancangan Perangkat Keras}

Berdasarkan perancangan alat Bagunan Sistem Pengendali Suhu Kelembaban dan Cahaya Pada Rumah Walet Berbasis Mikrokontroller, maka dibawah ini dijelaskan perancangan perangkat keras untuk sistem ini. Pada perancangan desain Bangunan sisntem kendali suhu kelembaban dan cahaya ini menggunakan sensor DHT11 untuk suhu dan kelembaban dan Sensor LDR untuk cahaya.

\subsection{Perancangan Perangakat Lunak}

Pemilihan software IDE Arduino didalam perancangan perangkat lunak ini karena kemudahan proses coding yang dapat mempermudah dalam penulisan program sebab telahtersedia library sebagai acuan dalam proses coding, serta settingan yang mudah pada saat program akan diupload pada perangkat kerasnya. Dengan model teknisnya sebagai berikut

a. Program yang telah dibuat pada software IDE Arduinoakan tersimpan dengan ekstensi arduino file.

b. Proses kompailer akan dilakukan langsung setelah file telah tersimpan dan dapat dilihat apakah terjadi pesan error/tidak.

c. Sebelum proses upload, terlebih dahulu periksa COM dan tipe Modul Arduino yang sesuai.

d. Dengan demikian program yang telah dibuat dan diuploaddapat diuji cobakan dengan melihat gerakan-gerakan robot.

\subsection{Prinsip Kerja Alat}

Pada saat pengguna menyambung daya listrik, saklar ON/OFF ditekan maka daya akan terhubung ke arduino. Didalam arduino ada komponen IC L7805 yang berfunsi untuk menurunkan tegangan dari $12 \mathrm{~V}$ dari adaptor menjadi $5 \mathrm{~V}$. karena tegangan yang di butuhkan oleh LCD, DHT11, sensor LDR, Motor Servo dan Relay adalah 5V sehingga pengguna dapat mengambil tegangan 5V dari arduino uno R3 Atmega 328 guna untuk memberikan supply tegangan ke LCD, DHT11, sensor LDR, Motor Servo dan relay, maka secara otomatis alat akan bekerja LCD akan menampilkan data suhu kelembaban dan cahaya yang dideteksi oleh sensor DHT11 dan sensor LDR pada saat sensor mendeteksi suhu rendah maka secara otomatis relay akan aktif untuk menyambungkan daya ke heater dan FAN, sehingga heater akan menghasilkan panas yang akan di bantu oleh kipas untuk menyebarkan panasnya ke seluruh ruangan untuk menormalkan kembali suhu, dan apabila suhu dalam ruangan tinggi maka relay akan aktif untuk menyambungkan daya ke penyemprot/spray, sehingga penyemprot akan aktif untuk menyiram ruangan agar suhunya normal kembali. Apabila cahaya dalam ruangan melebihi 0.5 FC maka tirai akan tertutup yang digerakkan oleh motor servo. Apabila cahaya dalam runagan kurang $0.5 \mathrm{FC}$ maka tirai akan terbuka begitulah secara otomatis terus menerus. 


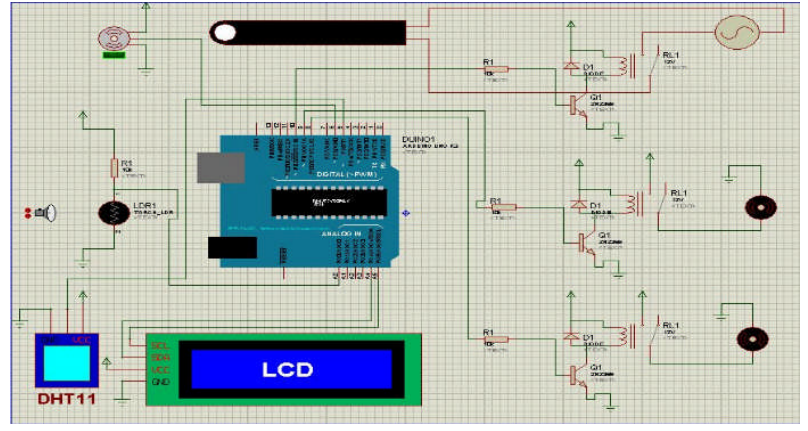

Gambar 7 Skematik Rangkaian Perancangan Alat

\subsection{Pengujian Perangkat keras}

Perangkat keras sebelum digunakan dalam sistem, maka terlebih dahulu dilakukan tahap-tahap pengujian alat dan rangkaian. Tujuan pengujian perangkat keras adalah untuk mengetahui ketepatan dan ketelitian dari perangkat keras yang kita buat, sehingga dengan melakukan pengujian secara bertahap pada masing- masing rangkaian akan diketahui kekuranganyang mungkin bisa untuk lebih diperbaiki lagi, meski ada beberapa alat yang sulit untuk dicoba perbagian dikarenakan terbatasnya peralatan. Adapun pengujian yang dilakukan dengan menggunakan system pengujian black box sebagaimana yang telah dijelaskan pada bab sebelumnya. Dan pengujian Perangkat keras sebelum digunakan dalam sistem, maka terlebih dahulu dilakukan tahap-tahap pengujian alat dan rangkaian. Adapun tujuan pengujian perangakat keras yang akan kita gunakan ialah untuk mengetahui apakah modul yang akan digunakan dapat berfungsi dengan baik atau tidak sehingga tidak menghambat kita dalam pembuatan alat.

\subsection{Pengujian Modul Arduino Uno R3 Atmega328}

Untuk memastikan Arduino telah terpasang dengan benar dan dapat berkomuniasi dengan interaktif maka ia perlu diuji.

1. Jalankan IDE Arduino dengan menjalankan file arduino.exe pada software Arduino.

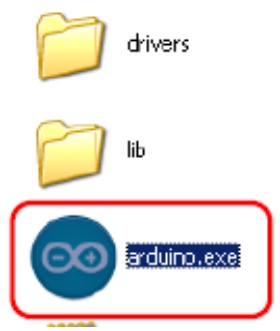

\section{Gambar 8 Aplikasi IDE Arduino}

2. Jalankan menu Tools $\rightarrow$ Board kemudian pilih tipe papan yang sesuai.

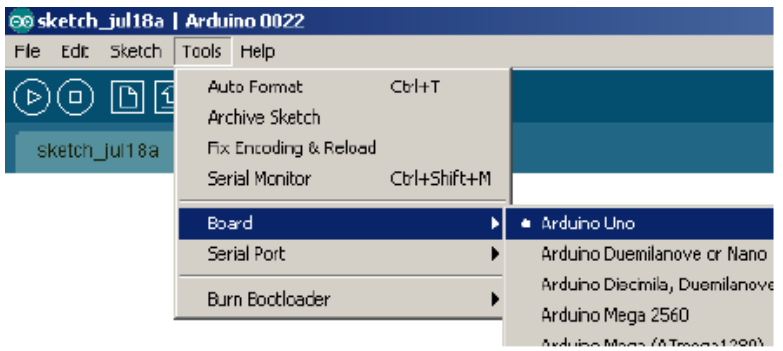

Gambar 9 Pemilihan Jenis Board Arduino 
3. Jalankan menu File $\rightarrow$ Examples $\rightarrow$ 1.Basic $\rightarrow$ Blink. Ini adalah program sederhana yang fungsinya adalah membuat lampu LED menyala berkedip- kedip.

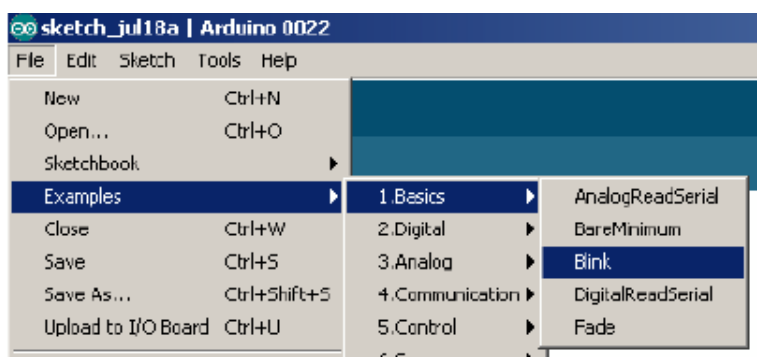

Gambar 10 Pemilihan Contoh Program

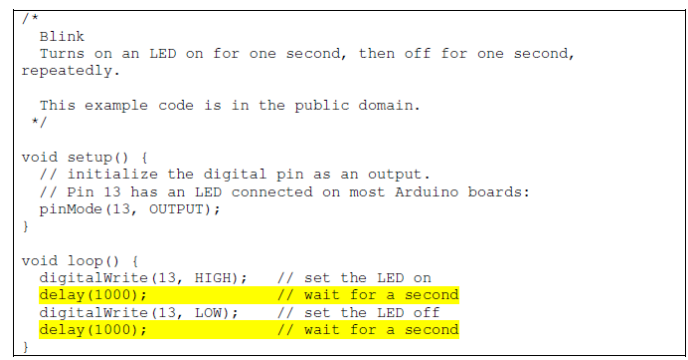

Gambar 11 Contoh Program LED

Bagian itu adalah perintah untuk menunda aliran program selama satu detik (1000 mili detik).Jadi bila lampu LED diperintahkan menyala pada baris sebelumnya, maka dengan perintah delay () lampu itu akan bertahan menyala selama satu detik sebelum ia diperintahkan untuk padam pada baris berikutnya. Mangubah ke dua angka 1000 itu menjadi 200 agar interval nyala-padam menjadi lebih pendek. Pada toolbar klik tombol Upload untuk memuat sketch tersebut kedalam papan Arduino.

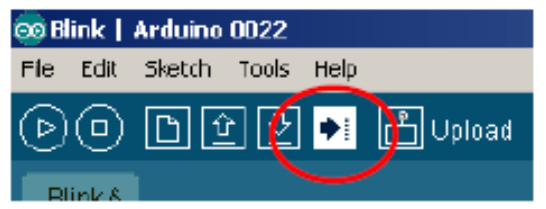

Gambar 12 Tombol Upload Program

Jika Anda cukup beruntung maka sketch akan dimuat, ditandai dengan pesan berhasil seperti di bawah ini.

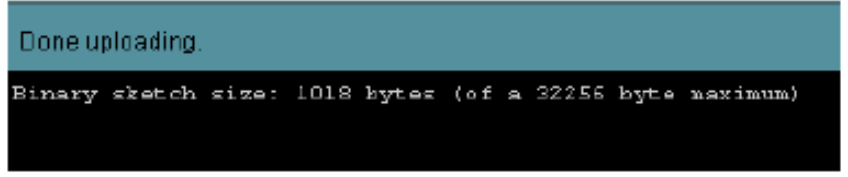

Gambar 13 Pesan Tanda Berhasil Upload Program

Namun jika kurang beruntung (seperti pada kebanyakan kasus umumnya) maka akan muncul pesan kesalahan seperti berikut.

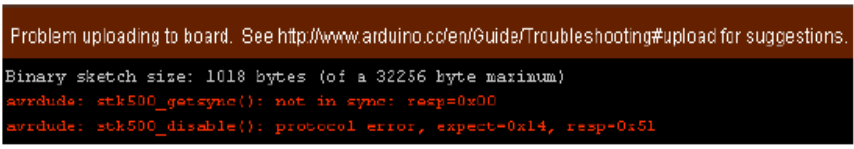

Gambar 14 Pesan Tanda Gagal Upload Program 
Solusinya cukup mudah, yaitu cukup mengganti pilihan serial port melalui menu Tools $\rightarrow$ Serial Port. Jika Anda tidak yakin pada port nomor berapa papan Arduino itu terhubung, coba pilih sebuah nomor port lalu jalankan upload sepertilangkah sebelumnya. Jika pesan kesalahan masih muncul, ganti nomor port-nya dan lakukan berulang-ulang ampai upload berhasil.

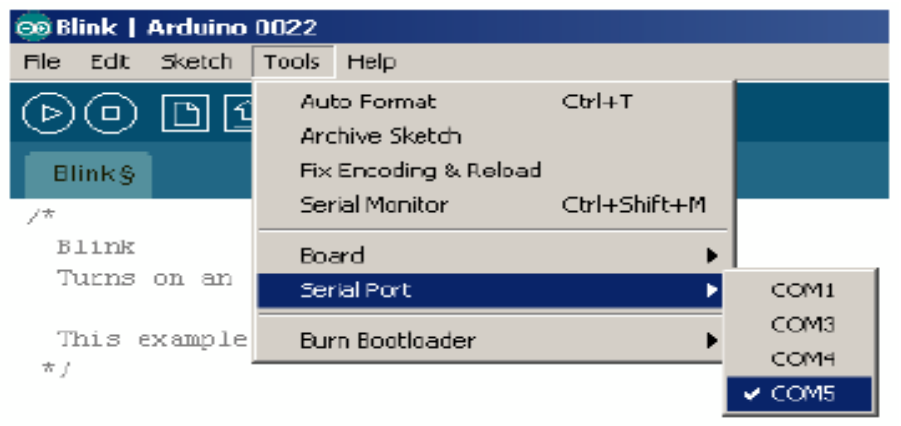

Gambar 15 Pemilihan COM

\subsection{Uji BlackBox}

Tabel 1 Tabel Pengujian

\begin{tabular}{|c|l|l|c|}
\hline No & \multicolumn{1}{|c|}{ Pengujian } & Hasil yang diharapkan & Keterangan \\
\hline 1 & \multicolumn{1}{|c|}{ On Power Supply } & $\begin{array}{l}\text { Alat akan menyala LCD } \\
\text { akan menampilkan nilai } \\
\text { suhu kelembaban dan } \\
\text { nilai cahaya }\end{array}$ & sesuai \\
\hline 2 & $\begin{array}{l}\text { Suhu }<26^{0} \mathrm{C} \text { kelembaban }<65 \\
\mathrm{RH}\end{array}$ & Heater dan kipas aktif & sesuai \\
\hline 3 & $\begin{array}{l}\text { Suhu }>29^{0} \mathrm{C} \text { kelembaban }>95 \\
\text { RH }\end{array}$ & Penyemprot aktif & sesuai \\
\hline 4 & Cahaya $>0.5 \mathrm{fc}$ & Tirai tertutup & sesuai \\
\hline 5 & Cahaya $<0.5 \mathrm{fc}$ & Tirai terbuka & sesuai \\
\hline
\end{tabular}

\section{KESIMPULAN}

Dari seluruh proses pengerjaan tugas akhir ini mulai dari pengerjaan penulisan sampai ke pengerjaan sistemnya, penulis dapat menarik beberapa kesimpulan, yaitu:

1. Alat yang telah dirancang dapat mengenandalikan suhu, kelembaban dan cahaya dalam ruangan (rumah walet).

2. Hasil pengujian alat menunjukkan sensor LDR bekerja pada intensitas cahaya $0.5 \mathrm{fc}$ dan sensor DHT11 bekerja pada suhu $26-29^{\circ} \mathrm{C}$ dan kelembaban $65-95 \mathrm{RH}$ 


\section{DAFTAR PUSTAKA}

[1] Nazzarudin dan A. Widodo. 2008. "Sukses Merumahkan Walet". Jakarta. Penebar Swadaya.

[2] Mardiastuti, A., Y. A. Mulyani, J. Sugarjito, L. N. Ginonga, I. Maryanto, A. Nugraha dan Ismail, 1998. "Teknik pengusahaan Burung Walet rumah, pemanenan sarang, dan penanganan pasca panen". Laporan Riset Unggulan Terpadu IV. Kantor Menteri Negara Riset dan Teknologi, Dewan Riset Nasional, Jakarta.

[3] Fachrul, 2015. "Rangkaian Sensor Kelembaban dan Suhu Menggunakan DHT22”, Copyright @2015 Elektronika Newbie

[4] Husanto dan Thomas 2007. "PLC (Progrmmable Logic Control) FP Sigma". Yogyakarta: ANDI OFFSET

[5] Artanto, Dian, 2012. "Interaksi Arduino dan Lab VIEW". Jakarta : Elex Media Komputindo

[6] Afrie Setiawan 2011. "20 Aplikasi mikrokontroler ATmegal6 menggunakan Baccom $A V R$ ". Yogyakarta: ANDI OFFSET.

[7] Muhammad Syahwil, 2013. "Panduan Mudah Simulasi dan Praktek Mikrokontroler Arduino". Yogyakarta: ANDI OFFSET..

[8] Syarkawi, 2007. "Pengontrolan (Posisi) Motor Servo AC dengan dengan Metoda Pengaturan Volt/Hertz", Universitas Andalas: Medan. 